\title{
Cell Division Inhibition in Salmonella typhimurium Histidine- Constitutive Strains: an ftsI-Like Defect in the Presence of Wild-Type Penicillin-Binding Protein 3 Levels
}

\author{
DAVID A. CANO,${ }^{1}$ CHAKIB MOUSLIM,${ }^{1}$ JUAN A. AYALA, ${ }^{2}$ FRANCISCO GARCÍA-DEL PORTILLO,${ }^{2}$ \\ AND JOSEP CASADESÚS ${ }^{1 *}$ \\ Departamento de Genética, Facultad de Biología, Universidad de Sevilla, Seville 41080, ${ }^{1}$ and Centro de Biología \\ Molecular Severo Ochoa, CSIC-Universidad Autónoma de Madrid, Cantoblanco, Madrid 28049, ${ }^{2}$ Spain
}

Received 6 April 1998/Accepted 11 July 1998

\begin{abstract}
Histidine-constitutive $\left(\mathrm{His}^{\mathrm{c}}\right)$ strains of Salmonella typhimurium undergo cell division inhibition in the presence of high concentrations of a metabolizable carbon source. Filaments formed by His ${ }^{c}$ strains show constrictions and contain evenly spaced nucleoids, suggesting a defect in septum formation. Inhibitors of peni-


His $^{c}$ septation defect is caused neither by reduced PBP3 synthesis nor by reduced PBP3 activity. Gross modifications of peptidoglycan composition are also ruled out. D-Cycloserine, an inhibitor of the soluble pathway producing peptidoglycan precursors, causes phenotypic suppression of filamentation, suggesting that the septation defect of His ${ }^{c}$ strains may be caused by scarcity of PBP3 substrate.
\end{abstract}

When histidine-constitutive $\left(\mathrm{His}^{\mathrm{c}}\right)$ mutants of Salmonella typhimurium were first isolated, the authors noted that high levels of histidine biosynthetic enzymes caused wrinkled colony morphology on $2 \%$ glucose plates (25). Wrinkledness reflects cell filamentation $(12,19)$, which is triggered by overproduction of hisH and his $F$ gene products $(5,9,19)$. A similar response has been described for Escherichia coli (11). HisH and HisF are subunits of the heterodimeric imidazole-glycerolphosphate synthase $(1,34)$, which catalyzes the formation of imidazole-glycerol-phosphate (IGP) with release of the purine precursor AICAR (5-aminoimidazole-4-carboxamide ribonucleotide) $(17,26)$. However, division inhibition does not require metabolic flow through the histidine biosynthetic pathway, suggesting that $\mathrm{HisH}$ and $\mathrm{HisF}$ trigger filamentation through an activity unrelated to IGP synthesis $(10,19)$. The involvement of AICAR has been also ruled out $(10,11)$. In both $S$. typhimurium and E. coli, the cell division defect of $\mathrm{His}^{\mathrm{c}}$ strains is unrelated to the SOS response and does not involve the cell division inhibitor $\operatorname{SulA}(11,12)$. We show below that the cell division defect of $S$. typhimurium His ${ }^{\mathrm{c}}$ strains is a block in septum formation, as proposed by Frandsen and D'Ari (11). We also describe the unexpected finding that strains that overproduce IGP synthase contain wild-type levels of active penicillin-binding protein 3 (PBP3). These contradictory data are tentatively reconciled by the ability of $\mathrm{D}$-cycloserine to suppress filamentation in $\mathrm{His}^{\mathrm{c}}$ mutants. The latter observation suggests that HisHF overproduction may cause a shortage in PBP3 substrate.

Filament formation by $\mathrm{His}^{\mathbf{c}}$ strains. Mid-exponential-phase cultures of strains LT2 (his ${ }^{+}$) and TR6753 (hisO1242 [5, 16]) were observed under the microscope by using Hiraga's fluophase combined method, a procedure that permits the simultaneous observation of nucleoids and cells (15). Nucleoid staining was achieved with DAPI (4',6-diamino-2-phenylindole). The His ${ }^{\mathrm{c}}$ strain formed long filaments which contained

* Corresponding author. Mailing address: Departamento de Genética, Facultad de Biología, Universidad de Sevilla, Apartado 1095, Seville 41080, Spain. Phone: 3495455 7105. Fax: 34954557104. E-mail: genbac@cica.es. evenly spaced nucleoids, indicating that their division defect is unrelated to DNA synthesis or chromosome partition (Fig. 1). Moreover, the presence of blunt constrictions indicates that the division block lies beyond the stage of FtsZ action (8). The filaments are similar in morphology and length to those formed by $f t s I$ and fts $A$ mutants of $E$. coli (8). The ftsI gene encodes $\mathrm{PBP} 3$, an essential cell division protein involved in septum formation (27). FtsA is a membrane-bound protein that interacts with PBP3 $(22,31)$. A difference is that ftsI and fts $A$ mutants are conditional (thermosensitive) lethals unable to form colonies under restrictive conditions $(3,18)$, while the filaments produced by $\mathrm{His}^{\mathrm{c}}$ strains of $S$. typhimurium in the presence of $2 \%$ glucose give rise to colonies which are distinctly wrinkled $(9,19,25)$.

Antibiotics that inhibit PBP3, such as aztreonam and azlocillin, produce phenocopies of ftsI mutants in E. coli (29). Based on this precedent, we investigated whether PBP3 inhibitors were able to reproduce the filamentation phenotype of His ${ }^{c}$ strains. Addition of aztreonam ( $1 \mathrm{mg} / \mathrm{liter})$ to a culture of strain LT2 triggered filament formation (Fig. 1C), and the filaments were identical in morphology and length to those formed by the His ${ }^{c}$ strain TR6753 (Fig. 1A). The same effect was induced by azlocillin (data not shown). At the concentrations used, these antibiotics inhibit specifically PBP3 (21). These observations suggest that His ${ }^{\mathrm{c}}$ strains of $S$. typhimurium behave as ftsI mutants.

Additional evidence against an FtsA-like defect was provided by the failure of a plasmid carrying the $E$. coli fts $A$ gene to relieve cell division inhibition when introduced in strain TR6753. If $\mathrm{His}^{\mathrm{c}}$ strains were fts $A$-like, a plasmid-borne fts $A$ gene should restore the FtsA/FtsZ ratio (6), thereby causing a certain degree of suppression. However, the actual result was that pMFV26, an fts $A^{+}$plasmid provided by Miguel Vicente (CIB-CSIC, Madrid, Spain), failed to relieve septation inhibition. The conclusion that $\mathrm{His}^{\mathrm{c}}$ strains behave as ftsI (rather than $f$ ts $A$ ) mutants receives further support from the ability of D-cycloserine to suppress filamentation (see below).

HisHF overproduction does not cause reduced synthesis of PBP3. The levels of $\mathrm{PBP} 3$ produced by $\mathrm{HisO}^{+}$and $\mathrm{HisO}^{c}$ strains were compared by using envelope extracts from mid- 


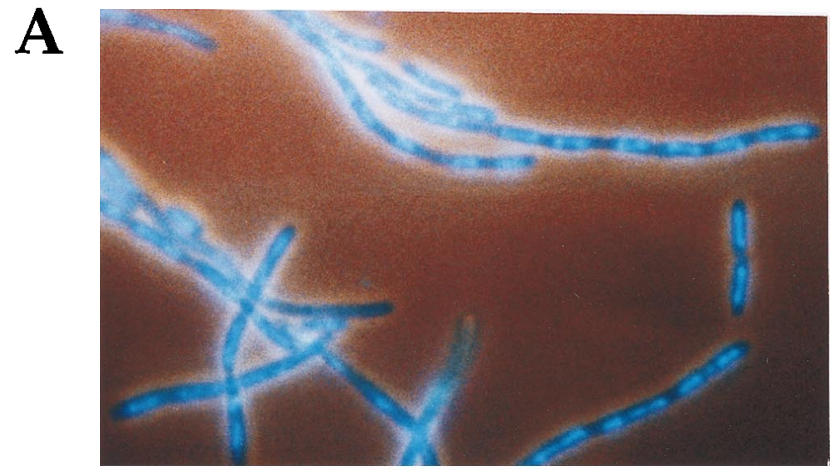

B
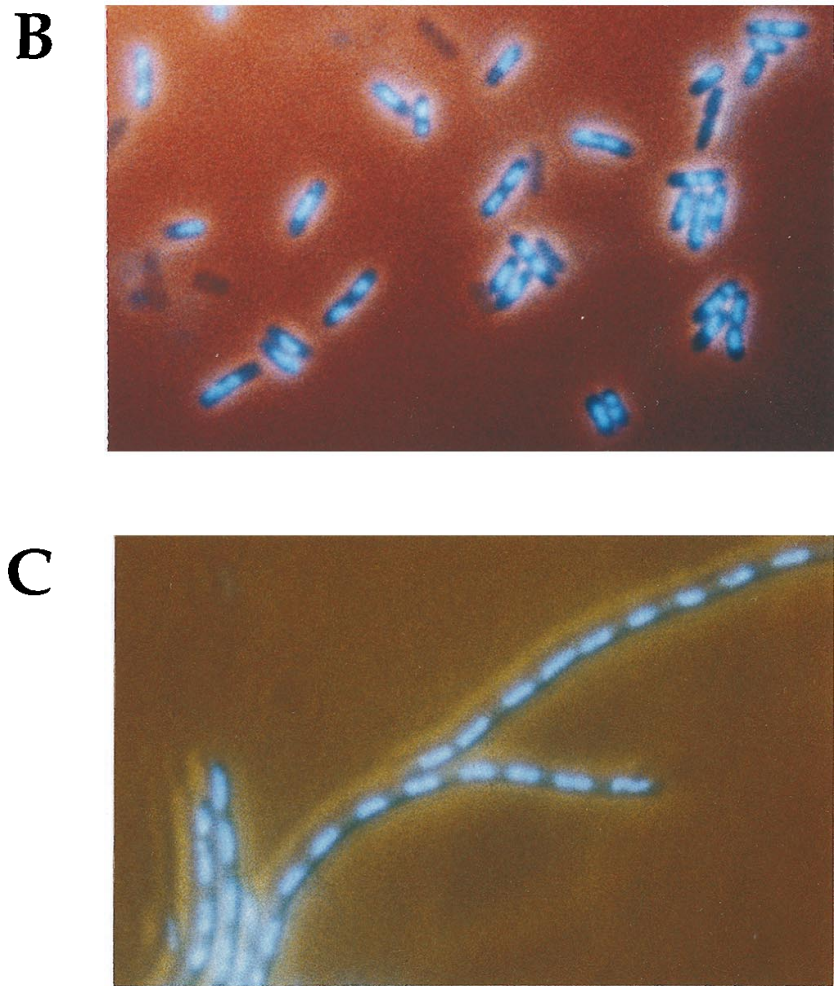

FIG. 1. Microscopic photographs of cells and filaments prepared with Hiraga's fluo-phase combined method (15). (A) Filaments formed by the $\mathrm{His}^{\mathrm{c}}$ strain TR6753 grown in E medium containing 2\% glucose. (B) An isogenic $\mathrm{His}^{+}$strain (LT2) grown under the same conditions does not form filaments. (C) Addition of aztreonam to a culture of strain LT2 in E medium induces filaments identical to those formed by a His ${ }^{\mathrm{c}}$ strain in high-glucose medium (compare panels A and C). Bar, $5 \mu \mathrm{m}$.

exponential-phase cultures (optical density at $600 \mathrm{~nm}, 0.5$ to 0.6 ) in E medium containing 2\% glucose (33). Envelope proteins were fractionated by sodium dodecyl sulfate (SDS)-polyacrylamide gel electrophoresis (8\% acrylamide) and detected by immunoblotting against a polyclonal anti-PBP3 serum (21). The levels of $\mathrm{PBP} 3$ protein are similar in $\mathrm{HisO}^{+}$and $\mathrm{HisO}^{\mathrm{c}}$ strains (Fig. 2); densitometric analysis (not shown) confirmed the absence of differences. Thus, the cell division defect associated with IGP synthase overproduction is not caused by reduced synthesis of PBP3. An additional observation is that the electrophoretic mobilities of $\mathrm{PBP} 3$ are similar in $\mathrm{HisO}^{+}$and

\section{A $\quad$ B $\quad$ C $\quad$ D}

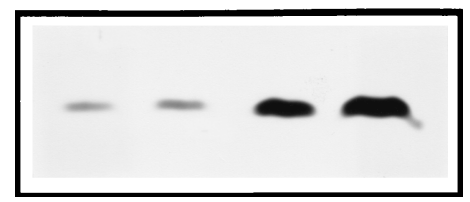

FIG. 2. Immunodetection of PBP3 from the wild type (lanes A and C) and the His ${ }^{\mathrm{c}}$ strain TR6753 (lanes B and D). Lanes A and B contain membrane vesicles corresponding to $80 \mu \mathrm{g}$ of protein in a final reaction volume of $20 \mu \mathrm{l}$. Lanes $\mathrm{C}$ and D contain membrane vesicles corresponding to $120 \mu \mathrm{g}$ of protein in a final volume of $20 \mu \mathrm{l}$.

$\mathrm{HisO}^{c}$ strains, thereby eliminating the occurrence of gross structural changes in the protein.

HisHF overproduction does not cause reduced activity of PBP3. As an indicator of the functionality of PBP3 in membrane extracts from $\mathrm{HisO}^{+}$and $\mathrm{HisO}^{c}$ strains, we analyzed their capacities to bind covalently ${ }^{3} \mathrm{H}$-labelled benzylpenicillin (2). Cultures were prepared as described above. Protein separation was performed on an SDS-polyacrylamide gel (2). Radioactivity was detected by fluorography $(28,30)$. Protein quantitation was performed by the method of Bradford (4). No differences in penicillin binding were found (Fig. 3 and densitometric data not shown). A side observation is that the remaining high-molecular-weight PBPs were also unaffected (Fig. 3).

Peptidoglycan composition of His ${ }^{\mathbf{c}}$ strains. To investigate the possibility that $\mathrm{His}^{\mathrm{c}}$ strains might synthesize an abnormal cell wall, we prepared peptidoglycan extracts from strains LT2 and TR6753 grown in E medium containing 2\% glucose. Concentrated exponential cultures containing approximately $10^{11}$ bacterial cells were cooled to $4^{\circ} \mathrm{C}$, centrifuged at $12,000 \times g$ for $15 \mathrm{~min}$, and resuspended in $3 \mathrm{ml}$ of phosphate-buffered saline, $\mathrm{pH}$ 7.4. The suspension was mixed 1:1 ( $\mathrm{vol} / \mathrm{vol})$ with a boiling solution of $8 \%$ SDS (24). The SDS-insoluble material was washed in distilled water (13). Peptidoglycan was digested with Cellosyl muramidase $(20 \mu \mathrm{g} / \mathrm{ml})$ (Hoechst, Sommerville, N.J.); this treatment yields muropeptides of low molecular weight (23). The reaction was stopped in a boiling bath for $5 \mathrm{~min}$.

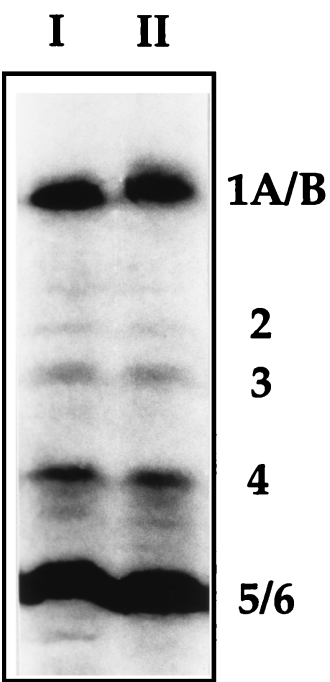

FIG. 3. Binding of ${ }^{3} \mathrm{H}$-labelled benzylpenicillin to cell envelopes from exponentially growing cells of the $\mathrm{His}^{+}$strain LT2 (lane I) and the His ${ }^{\mathrm{c}}$ strain TR6753 (lane II). PBPs are numbered on the right by standard nomenclature (27). 
TABLE 1. Muropeptide composition of peptidoglycan from $\mathrm{His}^{+}$ and $\mathrm{His}^{\mathrm{c}}$ strains and from a His ${ }^{+}$strain treated with aztreonam

\begin{tabular}{|c|c|c|c|c|c|c|}
\hline \multirow{3}{*}{ Sample } & \multicolumn{5}{|c|}{ Relative abundance $(\mathrm{mol} \%)^{a}$} & \multirow{3}{*}{$\begin{array}{c}\text { Cross- } \\
\text { linkage } \\
(\%)\end{array}$} \\
\hline & \multirow{2}{*}{ Monomers } & \multicolumn{2}{|c|}{ Dimers } & \multirow{2}{*}{ Trimers } & \multirow{2}{*}{ Lpp } & \\
\hline & & D-D & L-D & & & \\
\hline LT2 $\left(\mathrm{His}^{+}\right)$ & 65.2 & 27.7 & 2.9 & 4.12 & 9.25 & 38.8 \\
\hline TR6753 $\left(\mathrm{His}^{\mathrm{c}}\right)$ & 66.9 & 26.4 & 3.2 & 3.2 & 9.0 & 36.3 \\
\hline LT2 (with aztreonam) & 66.0 & 26.2 & 3.0 & 4.6 & 8.2 & 38.5 \\
\hline
\end{tabular}

${ }^{a}$ Muropeptides are grouped according to structural similarities (13). D-D are dimeric muropeptides cross-linked by a D-D peptide bridge; L-D are dimeric muropeptides cross-linked by an L-D peptide bridge. Trimers are trimeric muropeptides cross-linked by D-D peptide bridges. Lpp are muropeptides bound to the C-terminal dipeptide of Braun's lipoprotein $(13,14)$.

Insoluble material was removed by centrifugation $(1,000 \times g$, $10 \mathrm{~min}$ ). Peptidoglycan composition was determined by highperformance liquid chromatography analysis $(13,14)$. The main conclusions are that (i) abnormal peptidoglycan muropeptides were not found and (ii) gross differences in peptidoglycan composition or organization were not found between $\mathrm{HisO}^{+}$ and $\mathrm{HisO}^{\mathrm{c}}$ strains (Table 1). These experiments do not rule out the formation of an abnormal PBP3 substrate but certainly exclude the possibility that any unusual substrate is incorporated into growing peptidoglycan chains. This absence of differences does not eliminate the possibility that $\mathrm{His}^{\mathrm{c}}$ strains may have a defect in the reaction catalyzed by PBP3; peptidoglycan from strain LT2 treated with the PBP3 inhibitor aztreonam showed

A



B



FIG. 4. D-Cycloserine causes phenotypic suppression of the cell division defect of His ${ }^{\mathrm{c}}$ strains. (A) Strain TR6753 grown in E medium contains only filaments. (B) The presence of D-cycloserine causes suppression of filamentation; strain TR6753 forms rod-shaped cells. Bar, $10 \mu \mathrm{m}$. also standard composition (Table 1). In fact, a well-known and surprising feature of cell wall synthesis is that the global peptidoglycan composition remains unaltered under conditions that cause major changes in cell shape (20).

D-Cycloserine causes phenotypic suppression of the cell division defect of $\mathrm{His}^{\mathbf{c}}$ strains. To explore the possibility that the septation defect of $\mathrm{His}^{\mathrm{c}}$ strains might be caused by lowered levels of PBP3 substrate, we investigated whether D-cycloserine was able to cause phenotypic suppression of filamentation in a $\mathrm{His}^{\mathrm{c}}$ mutant. D-Cycloserine reduces the number of pentapeptide side chains in peptidoglycan and increases the number of tripeptides (21), an effect caused by inhibition of D-alanine-Dalanine ligase and alanine racemase (32). The resulting imbalance increases septation at the expense of elongation, giving rise to rounded cells in the wild type and restoring cell division in $\mathrm{FtsI}^{-}$mutants (3).

$\mathrm{His}^{\mathrm{c}}$ strains formed wrinkled colonies on both green plates and E plates containing $2 \%$ glucose. In the presence of D-cycloserine ( $20 \mathrm{mg} /$ liter), the colonies formed by the $\mathrm{HisO}^{\mathrm{c}}$ strain TR6753 and those formed by the wild type were identical: smooth and small. For microscopic observation of cultures, strains LT2 and TR6753 were grown in E medium containing 2\% glucose and $15 \mathrm{mg}$ of D-cycloserine per liter. Exponential cultures were transferred to agar-coated slides and photographed under phase-contrast optics (7). Strain LT2 formed rounded cells (data not shown). Strain TR6753 underwent nearly complete suppression of filamentation and formed rod-shaped cells (Fig. $4)$. Because these results strongly resemble those obtained with ftsI mutants of E. coli (3), we hypothesize that D-cycloserine may suppress the septation defect of $\mathrm{His}^{\mathrm{c}}$ strains by increasing PBP3 substrate. If this view is correct, the cell division defect of His $^{c}$ strains may be tentatively reformulated as a shortage of tripeptide side chains, the proposed substrate of the septal machinery (21).

This study was supported by grant PB93-649 from the Dirección General de Investigación Científica y Técnica of the Government of Spain and grant 97-109-96 from the Comunidad de Madrid.

We thank Miguel Vicente for the gift of pMFV26 and Boris Magasanik, Dick D'Ari, and Molly Schmid for helpful discussions. The assistance of Gloria Chacón, Ana Moreno, José Córdoba, and Luis Romanco is also appreciated.

\section{REFERENCES}

1. Alifano, P., R. Fani, P. Liò, A. Lazcano, M. Bazzicalupo, M. S. Carlomagno, and C. B. Bruni. 1996. Histidine biosynthetic pathway and genes: structure, regulation, and evolution. Microbiol. Rev. 60:44-69.

2. Ayala, J. A., C. Goffin, M. Nguyen-Distèche, and J. M. Ghuysen. 1994. Site-directed mutagenesis of penicillin-binding protein 3 of Escherichia coli: role of Val545. FEMS Microbiol. Lett. 121:251-256.

3. Begg, K. J., A. Takasuga, D. H. Edwards, S. J. Dewar, B. G. Spratt, H. Adachi, T. Ohta, H. Matsuzawa, and W. D. Donachie. 1990. The balance between different peptidoglycan precursors determines whether Escherichia coli cells will elongate or divide. J. Bacteriol. 172:6697-6703.

4. Bradford, M. M. 1976. A rapid and sensitive method for the quantitation of microgram quantities of protein utilizing the principle of protein-dye binding. Anal. Biochem. 72:248-254.

5. Casadesús, J., and J. R. Roth. 1989. Absence of insertions among spontaneous mutants of Salmonella typhimurium. Mol. Gen. Genet. 216:210-216.

6. Dai, K., and J. Lutkenhaus. 1992. The proper ratio of FtsZ to FtsA is required for cell division to occur in Escherichia coli. J. Bacteriol. 174: $6145-6151$.

7. Donachie, W. D., K. J. Begg, and M. Vicente. 1976. Cell length, cell growth and cell division. Nature (London) 264:328-333.

8. Donachie, W. D., K. J. Begg, and N. F. Sullivan. 1984. Morphogenes of Escherichia coli, p. 27-62. In R. Losick and L. Shapiro (ed.), Microbial development. Cold Spring Harbor Laboratory Press, Cold Spring Harbor, N.Y.

9. Flores, A., and J. Casadesús. 1995. Suppression of the pleiotropic effects of HisH and HisF overproduction identifies four novel loci on the Salmonella typhimurium chromosome: osm H, sfiW, sfiX, and sfiY. J. Bacteriol. 177: 4841-4850.

10. Flores, A., M. Fox, and J. Casadesús. 1993. The pleiotropic effects of Sal- 
monella typhimurium his overexpression do not involve AICAR-induced mutagenesis. Mol. Gen. Genet. 240:360-364.

11. Frandsen, N., and R. D'Ari. 1993. Excess histidine enzymes cause AICARindependent filamentation in Escherichia coli. Mol. Gen. Genet. 240:348354.

12. Gibert, I., and J. Casadesús. 1990. sulA-independent division inhibition in His-constitutive strains of Salmonella typhimurium. FEMS Microbiol. Lett. 69:205-210.

13. Glauner, B., and U. Schwarz. 1983. The analysis of murein composition with high-pressure-liquid-chromatography, p. 29-34. In R. Hackenbeck, J. V. Höltje, and H. Labisnchinski (ed.), The target of penicillin. Walter de Gruyter, Berlin, Germany.

14. Glauner, B., J. V. Höltje, and U. Schwarz. 1988. The composition of the murein of Escherichia coli. J. Biol. Chem. 263:10088-10095.

15. Hiraga, S., H. Niki, T. Ogura, C. Ichinose, H. Mori, B. Ezaki, and A. Jaffé. 1989. Chromosome partitioning in Escherichia coli: novel mutants producing anucleate cells. J. Bacteriol. 171:1496-1505.

16. Johnston, H. M., and J. R. Roth. 1981. Genetic analysis of the histidine operon control region of Salmonella typhimurium. J. Mol. Biol. 145:715-734.

17. Klem, T. J., and V. J. Davisson. 1993. Imidazole glycerol phosphate synthase: the glutamine amidotransferase in histidine biosynthesis. Biochemistry 32: 5177-5186.

18. Lutkenhaus, J. 1993. Escherichia coli cell division. Curr. Opin. Genet. Dev. 3:783-788.

19. Murray, M. L., and P. E. Hartman. 1971. Overproduction of hisH and hisF gene products leads to inhibition of cell division in Salmonella. Can. J. Microbiol. 18:671-681.

20. Nanninga, N. 1991. Cell division and peptidoglycan assembly in Escherichia coli. Mol. Microbiol. 5:791-795.

21. Pisabarro, A. G., R. Prats, D. Vázquez, and A. Rodríguez-Tébar. 1986. Activity of penicillin-binding protein 3 from Escherichia coli. J. Bacteriol. 168:199-206.

22. Pla, J., A. Dopazo, and M. Vicente. 1990. The native form of FstA, a septal protein of Escherichia coli, is located in the cytoplasmic membrane. J. Bacteriol. 173:5097-5102.

23. Quintela, J. C., M. Caparrós, and M. A. de Pedro. 1995. Variability of peptidoglycan structural parameters in Gram-negative bacteria. FEMS Microbiol. Lett. 125:95-100.

24. Quintela, J. C., M. A. de Pedro, P. Zöllner, G. Allmaier, and F. García-del Portillo. 1997. Peptidoglycan structure of Salmonella typhimurium growing within cultured mammalian cells. Mol. Microbiol. 23:693-704.

25. Roth, J. R., D. N. Antón, and P. E. Hartman. 1966. Histidine regulatory mutants of Salmonella typhimurium. I. Isolation and general properties. J. Mol. Biol. 22:305-323.

26. Smith, D. W. E., and B. N. Ames. 1964. Intermediates in early steps of histidine biosynthesis. J. Biol. Chem. 239:1848-1855.

27. Spratt, B. G. 1975. Distinct penicillin-binding proteins involved in the division, elongation and shape of Escherichia coli K12. Proc. Natl. Acad. Sci. USA 72:2999-3003.

28. Spratt, B. G., and A. B. Pardee. 1975. Penicillin-binding proteins and cell shape in E. coli. Nature (London) 254:516-517.

29. Sykes, R. B., D. P. Bonner, K. Bush, and N. H. Georgopapadakou. 1982. Azthreonam (SQ 26,776), a synthetic monobactam specifically active against aerobic gram-negative bacteria. Antimicrob. Agents Chemother. 21:85-92.

30. Tamaki, S., H. Matsuzawa, and M. Matsuhashi. 1977. Cluster of $m r d A$ and $m r d B$ genes responsible for the rod shape and mecillinam sensitivity of Escherichia coli. J. Bacteriol. 141:53-57.

31. Tormo, A., J. A. Ayala, M. A. de Pedro, M. Aldea, and M. Vicente. 1986. Interaction of FtsA and PBP3 proteins in the Escherichia coli septum. J. Bacteriol. 166:985-992.

32. van Heijenoort, J. 1996. Murein synthesis, p. 1025-1034. In F. C. Neidhardt, R. Curtiss III, J. L. Ingraham, E. C. C. Lin, K. B. Low, B. Magasanik, W. S. Reznikoff, M. Riley, M. Schaechter, and H. E. Umbarger (ed.), Escherichia coli and Salmonella: cellular and molecular biology. American Society for Microbiology, Washington, D.C.

33. Vogel, H., and D. Bonner. 1956. Acetylornithase of Escherichia coli: partial purification and some properties. J. Biol. Chem. 218:97-106.

34. Winkler, M. E. 1996. Biosynthesis of histidine, p. 485-505. In F. C. Neidhardt, R. Curtiss III, J. L. Ingraham, E. C. C. Lin, K. B. Low, B. Magasanik, W. S. Reznikoff, M. Riley, M. Schaechter, and H. E. Umbarger (ed.), Escherichia coli and Salmonella: cellular and molecular biology. American Society for Microbiology, Washington, D.C. 